\title{
Pengaruh Kepemimpinan Servant dan Kepemimpinan Transformasional Terhadap Organizational Citizenship Behavior (OCB)
}

\author{
Melva Hermayanty Saragih ${ }^{1^{*}}$, Andana ${ }^{2}$, Farland Al Hafiz ${ }^{3}$, \\ Muhammad Alvin Meilando ${ }^{4}$ \\ 1,2,3,4 Management Department, BINUS Business School Undergraduate Program, \\ Bina Nusantara University \\ Jakarta 11480, Indonesia
}

melva.saragih@binus.ac.id; andana@binus.ac.id; Farland.hafiz@binus.ac.id; muhamad.meilando@binus.ac.id

*Correspondence: melva.saragih@binus.ac.id

\begin{abstract}
The purposes of this study was to examine the influence of Servant Leadership (SL) and Transformational Leadership (TL) on Organizational Citizenship Behavior (OCB) in a private company in Jakarta, Indonesia. The method used is multiple regression analysis, with a sample of 117 respondents. The results showed that Servant Leadership and Transformational Leadership had a significant effect on Organizational Citizenship Behavior. Thus, SL and TL are variables that are important to be applied in the company, especially in terms of increasing employee commitment and emotional attachment to the company organization.
\end{abstract}

Keywords: Servant Leadership; Transformational Leadership; Organizational Citizenship Behavior.

\begin{abstract}
ABSTRAK
Tujuan penelitian ini adalah untuk menguji pengaruh Servant Leadership (SL) dan Transformational Leadership (TL) terhadap Organizational Citizenship Behavior (OCB) pada sebuah perusahaan swasta di Jakarta, Indonesia. Metode yang digunakan adalah analisis regresi berganda, dengan jumlah sampel 117 responden. Hasil penelitian menunjukkan bahwa Kepemimpinan Servant dan Kepemimpinan Transformasional berpengaruh signifikan terhadap Organizational Citizenship Behavior. Dengan demikian SL dan TL merupakan variabel yang penting untuk diterapkan di perusahaan terutama dalam hal peningkatan komitmen karyawan dan keterikatan emosional pada organisasi perusahaan.
\end{abstract}

Kata Kunci: Servant Leadership; Transformational Leadership; Organizational Citizenship Behavior (OCB).

\section{PENDAHULUAN}

Pada era teknologi informasi yang berkembang sangat pesat saat ini, persaingan antar organisasi perusahaan menjadi sangat ketat, sehingga setiap pemimpin dan karyawan harus tanggap dalam mengikuti perubahan dan perkembangan yang terjadi agar dapat tetap bersaing. Dessler dalam Masram dan Mu'ah (2015) mengatakan bahwa globalisasi yang meluas meningkatkan persaingan, dan hal itu akan memberi dorongan bagi perusahaan untuk dapat diakui oleh dunia bisnis. Perusahaan juga dapat mengurangi biaya atau kerugian yang dapat terjadi akibat perilaku atau kurangnya kesiapan karyawan (human error). Karena itu agar perusahaan mampu tetap 
bersaing dalam kompetisi bisnis, diupayakan sedemikian rupa agar karyawan tetap produktif dan memiliki semangat perubahan ke arah yang lebih baik secara berkelanjutan.

Sumber daya manusia (SDM) merupakan investasi terbesar dalam suatu perusahaan. Oleh karena itu penting sekali mengelola SDM atau karyawan. Mengidentifikasi pengetahuan, keterampilan, dan kemampuan yang relevan dari para tim dapat mempengaruhi seluruh proses penempatan pekerjaan, yang mempengaruhi cara organisasi memilih, melatih, dan mempertahankan karyawan mereka (Stevens \& Campion, 1994). Meningkatkan tim yang lebih efektif mungkin meningkatkan kinerja tim, tetapi juga tingkat kepuasan karyawan dan pengusaha (Hogan \& Kaiser, 2005; Pacheco, 2015 dalam Inkpen dan Oster, 2018). Perusahaan mengharapkan agar semua karyawannya memiliki kinerja dan perilaku yang baik. Prilaku yang diharapkan ini termasuk di dalamnya prilaku in-role yakni prilaku dasar dimana karyawan melakukan pekerjaan sesuai dengan tugas dan kewajibannya atau sesuai dengan jobdesnya. Selain itu diharapkan pula, karyawan melakukan extra-role yakni kontribusi ekstra dalam menyelesaikan pekerjaan. Zhu, 2013 menyebutkan bahwa perilaku ekstra ini disebut dengan Organizational Citizenship Behavior (OCB). Karakter atau sifat-sifat yang merefleksikan OCB, antar lain suka membantu, bersedia bekerja sama (kooperatif), memiliki perhatian, dan bersungguh-sungguh dalam bekerja. Faktor yang mempengaruhi perilaku Organizational Citizenship Behavior adalah kepemimpinan. Menurut Robbins, Judge, dan Campbell (dalam R Salehzadeh, 2017) kepemimpinan adalah kemampuan untuk mempengaruhi kelompok menuju pencapaian visi atau serangkaian tujuan" Pemimpin dapat muncul dari kelompok atau ditunjuk secara resmi (Robbins et al., 2010). Teori sifat dan teori perilaku mencoba menentukan pemimpin yang efektif versus pemimpin yang tidak efektif, tetapi konteks memainkan peran penting dalam kesuksesan pemimpin (Robbins et al., 2010). Peran pemimpin dalam menciptakan komunikasi dan kerjasama cukup besar untuk memotivasi karyawan agar selalu memiliki inisiatif serta melakukan inovasi. Inovasi dalam hal ini termasuk perilaku OCB. Kemampuan pemimpin untuk mengarahkan perilaku karyawan agar mau melakukan inovasi, dan berani mengambil risiko dalam melakukan pekerjaannya yang memungkinkan karyawan mengalami kegagalan ketika berinovasi.

Menurut polling yang dilakukan oleh lembaga konsultan manajemen di Amerika ada 9 masalah komunikasi yang kerap terjadi dalam kepemimpinan, seperti dalam Gambar 1.

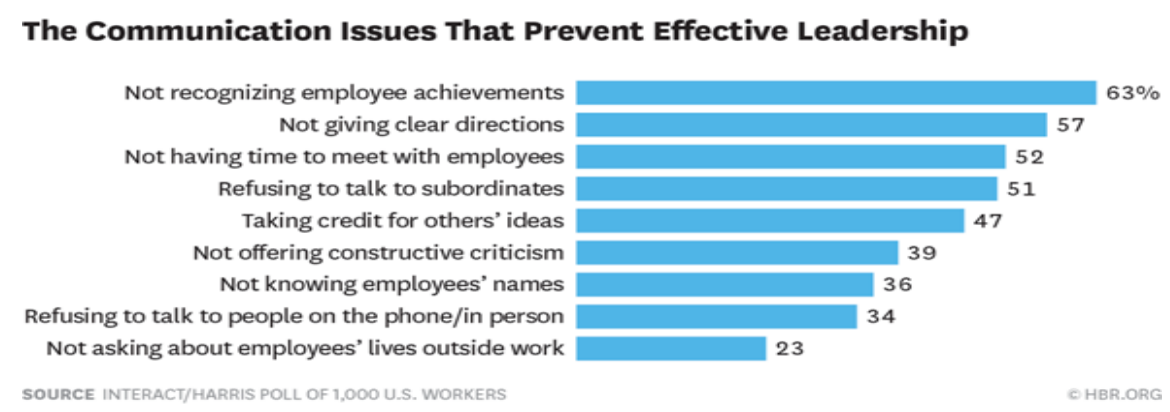

Gambar 1 The Communication Issues That Prevent Effective Leadership (Sumber: Interact/Harris poll of 1000 U.S workers)

Data dari Gambar 1 menunjukkan bahwa sebagian besar pemimpin tidak terlibat di saat yang penting ketika mereka sebenarnya dapat membantu karyawan untuk melihat mereka sebagai seseorang yang bisa dipercaya. Hal ini disayangkan, mengingat uang yang dihabiskan organisasi untuk melakukan survei dan reorganisasi karyawan, melibatkan konsultan dan mengimplementasikan perubahan yang direncanakan. Para pemimpin yang efektif tahu bahwa komunikasi yang sehat membutuhkan energi yang terkoneksi satu dengan yang lain, adanya pengakuan terhadap pencapaian karyawan, memberikan arah yang jelas, interaksi yang bermakna bersama karyawan, memberi umpan balik kepada seluruh karyawan sebagai urat nadi kehidupan berorganisasi yang sehat dalam perusahaan.

Penelitian ini mengambil sampel salah satu perusahaan swasta yang berlokasi di Jakarta sebagai objek studinya. Perusahaan ini adalah perusahaan Holding Company dan Jasa Konsultasi Management \& Keuangan yang berdiri pada tahun 2017. Dari studi yang dilakukan, didapat data turnover karyawan selama 4 periode terakhir yang dibagi setiap 6 bulan, seperti pada Tabel 1. 
Tabel 1: Data Turnover Rate Karyawan

\begin{tabular}{ccccc}
\hline Periode & $\begin{array}{c}\text { Masuk } \\
\text { perusahaan }\end{array}$ & $\begin{array}{c}\text { Keluar } \\
\text { perusahaan }\end{array}$ & $\begin{array}{c}\text { Jumlah } \\
\text { Karyawan }\end{array}$ & $\begin{array}{c}\text { Turnover } \\
\text { Rate }\end{array}$ \\
\hline Juli 2017 - Januari 2018 & - & - & 40 & - \\
\hline Januari 2018 - Juni 2018 & 40 & 3 & 77 & $1.79 \%$ \\
\hline Juli 2018 - Januari 2019 & 78 & 26 & 129 & $18.3 \%$ \\
\hline Januari 2019 - Juni 2019 & 61 & 24 & 166 & $34.7 \%$ \\
\hline
\end{tabular}

Berdasarkan data turnover karyawan pada Tabel 1, tercatat pada periode Juli 2017 s/d Januari 2018 ada kenaikan yang terus meningkat. Hal itu terjadi terus hingga periode Januari 2019 s/d Juli 2019. Adapun rate turnover-nya pada periode Januari $2018 \mathrm{~s} / \mathrm{d}$ Juni $2018=1,79 \%$ dan pada periode-periode selanjutnya rate naik sampai periode Januari 2019 s/d Juni $2019=34.7 \%$.

Sedangkan data absensi karyawan diperoleh data berikut:

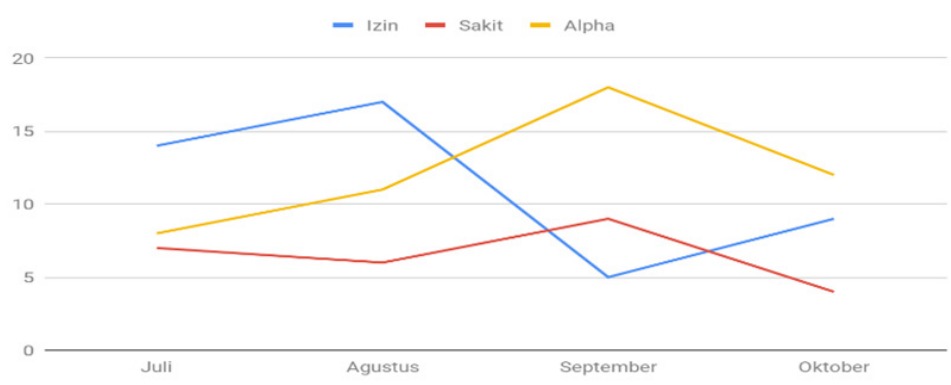

Gambar 2 Data Absensi

Berdasarkan data absensi tersebut terlihat adanya peningkatan persentase ketidakhadiran kayawan. Tercatat bulan Juli, ada 5 karyawan tidak masuk kerja tanpa keterangan yakni sejumlah 8 kali. Pada bulan Agustus ada 9 orang karyawan sebanyak 11 kali. Bulan September ada 14 orang sebanyak 18 kali dan 12 kali (12 orang). Pada periode Juli-Oktober, tercatat tidak ada hari besar nasional. Dari data turnover dan data absensi pada perusahaan tersebut tercatat bahwa ada kenaikan yang cukup berarti, karena itu penelitian ini hendak melihat pengaruh Servant Leadership dan Transformational Leadership yang dihubungkan dengan Organizational Citizenship Behaviour.

\section{METODE PENELITIAN}

Metode penelitian adalah bersifat asosiatif yang membuktikan hubungan dua variabel. Selain itu digunakan metode survey untuk memperoleh data dengan cara menyebarkan kuesioner terhadap populasi dan melakukan sejumlah pengamatan. Jumlah populasi yang ada 166 karyawan. Dari jumlah tersebut untuk menentukan sample digunakan rumus Slovin $(n=N /(1+(N x e))$. Maka sampel yang diambil berjumlah 117 karyawan.

Adapun metode yang digunakan dengan:

\section{Uji Validitas dan Reliabilitas}

Uji validitas merupakan alat uji untuk melihat sejauh mana alat ukur itu valid atau tidak untuk digunakan, dalam hal ini apakah alat ukur yang tertuang dalam item-item kuesioner valid atau tidak untuk dipakai. Uji validitas dalam penelitian ini menggunakan program SPSS, dengan melihat korelasi Product Moment Pearson. Jika $r$ hitung $\geq r$ table (uji 2 sisi dengan sig. 0,05), maka instrument atau item-item pertanyaan yang berkorelasi signifikan terhadap skor total dalam kuesioner dinyatakan valid.

Uji Reliabilitas atau uji keandalan merupakan alat uji yang melihat sejauh mana hasil pengukuran dengan alat itu dapat dipercaya atau diandalkan. Artinya alat ukur itu memiliki konsistensi dalam mengukur. Tinggi rendahnya reliabilitas ditunjukkan suatu angka yang disebut nilai koefien reliabilitas. Reliabilitas cukup memuaskan bila $\geq$ 0.700 . 


\section{Analisis Korelasi}

Korelasi Pearson Product Moment termasuk teknik statistik parametik yang menggunakan data interval dan ratio, digunakan utuk mencari hubungan antara variable bebas (X) Servant Leadership dan Transformational Leadership dan variable terikat (Y) Organizational Citizenship Behavior.

Untuk mengetahui signifikansi korelasi dengan membandingkan antara nilai probabilitas 0,05 dan nilai probabilitas sig. yaitu:

Hipotesis:

$\mathrm{Ho}=$ Antara variabel $\mathrm{X}$ dan variabel $\mathrm{Y}$ tidak berhubungan secara signifikan.

$\mathrm{Ha}=$ Antara variabel $\mathrm{X}$ dan variabel $\mathrm{Y}$ ada hubungan signifikan .

Keputusan yang dapat diambil:

- Ho diterima dan Ha ditolak (tidak signifikan), apabila nilai probabilitas $0.05 \leq \mathrm{Sig}$.

- Ho ditolak dan Ha diterima (signifikan), apabila nilai probabilitas $0.05 \geq$ Sig.

\section{Analisis Regresi Sederhana dan Berganda}

Analisis regresi adalah suatu teknik yang bertujuan untuk menguji pengaruh variabel bebas (independent) terhadap variabel terikat (dependent). Regresi linier sederhana digunakan apabila variabel terikat hanya dipengaruhi oleh satu variabel bebas. Sementara, regresi linier berganda digunakan apabila terdapat lebih dari satu variabel bebas yang mempengaruhi variabel terikat.

Persamaan Regresinya adalah:

$\mathrm{Y}=\mathrm{bo}+\mathrm{b} 1 \mathrm{X} 1+\mathrm{b} 2 \mathrm{X} 2+$ bnXn $+e$

Keterangan:

$\mathrm{Y}=$ variable dependen $\mathrm{X} 1, \mathrm{X} 2$,

$\mathrm{Xn}=$ Variabel independent

bo $=$ konstanta regresi

b1, b2 = koefisien regresi

$\mathrm{e}=0$ Hipotesis yang diterima jika: 1) Nilai sig (PValue) $<$ alpha, 2) Koefisien Regresi searah dengan hipotesis.

\section{HASIL DAN PEMBAHASAN}

\section{Analisis Regresi}

Dalam penelitian ini menggunakan analisis regresi sederhana dan regresi berganda. Sebagai variabel bebas adalah Servant Leadership (X1) dan Transformational Leadership (X2), sedangkan variabel terikat adalah Organizational Citizenship Behavior (Y). Framework penelitian digambarkan seperti pada Gambar 3.

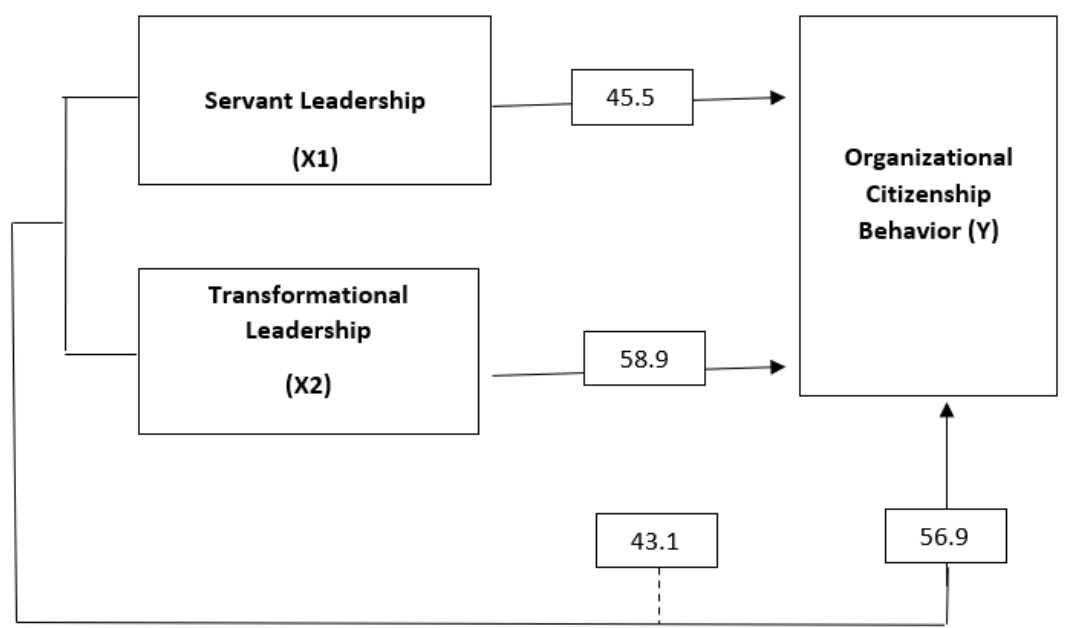

Gambar 3 Stuktur Hubungan dan Pengaruh X1, X2, terhadap Y 
Tabel 2 Model Summary (X1)

\begin{tabular}{lcccc}
\hline \multicolumn{5}{c}{ Model Summary $^{\mathbf{b}}$} \\
\hline Model & $\mathrm{R}$ & $\mathrm{R}$ Square & Adjusted R Square & Std. Error of the Estimate \\
\hline 1 &, $675^{\mathrm{a}}$ &, 455 &, 451 & 5,48269 \\
\hline $\begin{array}{l}\text { a. Predictors: (Constant), X1 } \\
\text { b. Dependent Variable }\end{array}$ & & & \\
\end{tabular}

1. Tabel 2 menunjukkan bahwa ada korelasi yang cukup kuat antara SL terhadap OCB karena nilai R square yang 0.455 berada pada rentang $0.40 \mathrm{~s} / \mathrm{d} 0.599$. Hubungan kedua variabel tersebut berarti berpengaruh sebesar $45.5 \%$, dan adanya faktor-faktor lain yang mempengaruhi sebesar $54.5 \%$.

2. Tabel 2 menunjukkan bahwa ada korelasi yang cukup kuat antara TL dan OCB karena nilai R square yang 0.675 berada pada rentang $0.60 \mathrm{~s} / \mathrm{d} 0.799$.

Tabel 3 ANOVA (X1)

\begin{tabular}{rlrrrrr}
\hline \multicolumn{7}{c}{ ANOVA $^{\text {a }}$} \\
\hline \multirow{2}{*}{1} & Model & Sum of Squares & Df & Mean Square & F & Sig. \\
\cline { 2 - 7 } & Regression & 2889,637 & 1 & 2889,637 & 96,129 &, $000^{\text {b }}$ \\
\cline { 2 - 7 } & Residual & 3456,892 & 115 & 30,060 & & \\
\cline { 2 - 6 } & Total & 6346,530 & 116 & & & \\
\hline
\end{tabular}

a. Dependent Variable: Y

b. Predictors: (Constant), X1

Uji ANOVA adalah sebuah analisis statistik yang menguji perbedaan antar variabel. Pengujian yang dilakukan oleh variabel X1 terhadap Y seperti yang tampak dalam Tabel 3 anova, terbukti adanya pengaruh signifikan SL (X1) terhadap OCB (Y).

Tabel 4 Coefficients (X1)

\begin{tabular}{|c|c|c|c|c|c|c|}
\hline \multicolumn{7}{|c|}{ Coefficients $^{a}$} \\
\hline & \multirow[t]{2}{*}{ Model } & \multicolumn{2}{|c|}{$\begin{array}{l}\text { Unstandardized } \\
\text { Coefficients }\end{array}$} & \multirow{2}{*}{$\begin{array}{c}\text { Standardized } \\
\text { Coefficients }\end{array}$} & \multirow[t]{2}{*}{$\mathrm{T}$} & \multirow{2}{*}{ Sig. } \\
\hline & & B & Std. Error & & & \\
\hline \multirow{2}{*}{1} & (Constant) & 15,998 & 3,132 & & 5,108 &, 000 \\
\hline & X1 & ,869 & ,089 & 675, & 9,805 &, 000 \\
\hline
\end{tabular}

Tabel 4 Coefficients menunjukkan adanya:

$\mathrm{Y}=15.998+0.869 \mathrm{X} 1$

$\mathrm{Y}=$ Organizational Citizenship Behavior

X1 = Servant Leadership

Kesimpulan dari persamaan regresi tersebut:

- Nilai konstanta 15.998 artinya jika tidak ada kenaikan nilai dari variabel SL (X1), maka nilai OCB (Y) adalah 15.998.

- Nilai SL (X1) 0.869 artinya jika tingkat SL semakin tinggi diterapkan pemimpin, maka OCB (Y) pun akan meningkat pada perusahaan tersebut. 
Analisis Regresi Sederhana Transformational Leadership (X2) Terhadap Organizational Citizenship Behaviour (Y)

Tabel 5 Variabel Masuk/Keluar (X2)

\begin{tabular}{lccc}
\hline \multicolumn{3}{c}{ Variabel Masuk/Keluar $^{\text {a }}$} \\
\hline Model & $\begin{array}{c}\text { Variabel } \\
\text { yang masuk }\end{array}$ & $\begin{array}{c}\text { Variabel } \\
\text { yang keluar }\end{array}$ & Metode \\
\hline 1 & $\mathrm{X} 2^{\mathrm{b}}$ & Masuk \\
\hline $\begin{array}{l}\text { a. Dependent Variable: Y } \\
\text { b. All requested variables entered }\end{array}$
\end{tabular}

Tabel 5 menunjukkan bahwa tidak ada variabel yang dikeluarkan sehingga dalam perhitungan regresi variabel bebas dimasukan.

Tabel 6 Model Summary (X2)

\begin{tabular}{ccccc}
\hline \multicolumn{4}{c}{ Model Summary $^{\mathrm{b}}$} \\
\hline Model & $\mathrm{R}$ & R Square & $\begin{array}{c}\text { Adjusted R } \\
\text { Square }\end{array}$ & $\begin{array}{c}\text { Std. Error of the } \\
\text { Estimate }\end{array}$ \\
\hline 1 &, $767^{\mathrm{a}}$ &, 589 &, 585 & 4,76321 \\
\hline
\end{tabular}

a. Predictors: (Constant), X2

b. Dependent Variable

1. Tabel 6 dengan angka R square yang menunjukkan SL (X2) terhadap OCB sebesar 0.589 mengindikasikan adanya hubungan yang cukup kuat, karena nilai berada pada rentang $0.40 \mathrm{~s} / \mathrm{d} 0.599$. Hubungan erat kedua variabel adalah $58.9 \%$, sedangkan sisanya $51.1 \%$ dipengaruhi oleh faktor-faktor lain.

2. Tabel 6 dengan angka R square yang menunjukkan TL(X2) terhadap OCB (Y) sebesar 0.767 mengindikasikan adanya hubungan yang kuat, karena nilai berada pada rentang $0.60 \mathrm{~s} / \mathrm{d} 0.799$.

Tabel 7 ANOVA (X2)

\begin{tabular}{llrrrrr}
\hline \multicolumn{7}{c}{ ANOVA $^{\text {a }}$} \\
\hline \multicolumn{1}{l}{ Model } & Sum of Squares & df & Mean Square & F & Sig. \\
\hline \multirow{3}{*}{1} & Regression & 3737,395 & 1 & 3737,395 & 164,729 &, $000^{\text {b }}$ \\
\cline { 2 - 7 } & Residual & 2609,135 & 115 & 22,688 & & \\
\cline { 2 - 7 } & Total & 6346,530 & 116 & & & \\
\hline
\end{tabular}

a. Dependent Variable: $\mathrm{Y}$

b. Predictors: (Constant), X1

Uji ANOVA untuk variabel X2 TL terhadap OCB (Y) dibuktikan dengan adanya pengaruh signifikan TL (X2) terhadap OCB (Y) pada perusahaan tersebut.

Tabel 8 Coefficients (X2)

\begin{tabular}{ccccccc}
\hline \multirow{2}{*}{ Model } & \multicolumn{2}{c}{$\begin{array}{c}\text { Unstandardized } \\
\text { Coefficients }\end{array}$} & $\begin{array}{c}\text { Standardized } \\
\text { Coefficients }\end{array}$ & t & Sig. \\
\cline { 3 - 6 } & & B & Std. Error & Beta & & \\
\hline \multirow{2}{*}{1} & (Constant) & 13,894 & 2,563 & & 5,421 &, 000 \\
\cline { 2 - 5 } & X2 &, 821 &, 064 &, 767 & 12,835 &, 000 \\
\hline
\end{tabular}

Tabel 8 menunjukkan adanya:

$\mathrm{Y}=13.894+0.821 \mathrm{X} 2$

$\mathrm{Y}=$ Organizational Citizenship Behavior

$\mathrm{X} 2=$ Transformational Leadership 
Kesimpulan dari persamaan regresi tersebut:

- Nilai konstanta 13.894 artinya jika tidak ada kenaikan nilai dari variabel TL (X2), maka nilai OCB (Y) adalah 13.894.

- Nilai TL (X2) 0.821 artinya jika tingkat TL semakin tinggi diterapkan pemimpin, maka OCB (Y) pun akan meningkat pada perusahaan tersebut.

\section{Analisis Regresi Berganda Servant Leadership (X1) dan Transformational Leadership (X2) terhadap Organizational Citizenship Behavior (Y)}

Tabel 9 sampai tabel 12 menunjukkan SL (X1) dan TL (X2) terhadap OCB (Y) dalam perhitungan SPSS 2.0.

Tabel 9 menunjukkan bahwa tidak ada variabel yang dikeluarkan sehingga dalam perhitungan regresi variabel bebas dimasukan.

Tabel 9 Variabel Masuk/Keluar (X2) dan (X2)

\begin{tabular}{cccc}
\hline \multicolumn{4}{c}{ Variabel Masuk/Keluar $^{\mathbf{a}}$} \\
\hline \multirow{2}{*}{ Model } & $\begin{array}{c}\text { Variables } \\
\text { Entered }\end{array}$ & $\begin{array}{c}\text { Variables } \\
\text { Removed }\end{array}$ & Method \\
\hline \multirow{2}{*}{1} & VAR00002 &. & Enter \\
& VAR00001 $^{\mathrm{b}}$ & $\cdot$ & \\
\hline
\end{tabular}

a. Dependent Variable: VAR00003

b. All requested variables entered

Tabel 10 Model Summary (X1) dan (X2)

\begin{tabular}{ccccc}
\hline \multicolumn{4}{c}{ Model Summary $^{\mathrm{b}}$} \\
\hline Model & $\mathrm{R}$ & $\mathrm{R}$ Square & $\begin{array}{c}\text { Adjusted R } \\
\text { Square }\end{array}$ & $\begin{array}{c}\text { Std. Error of the } \\
\text { Estimate }\end{array}$ \\
\hline 1 &, $755^{\mathrm{a}}$ &, 569 &, 562 & 4,88150 \\
\hline
\end{tabular}

a. Predictors: (Constant), VAR00002, VAR00001

b. Dependent Variable: VAR00003

- Tabel 10 yang menunjukkan angka R square 0.569 mengindikasikan bahwa OCB (Y) dipengaruhi oleh SL (X1) dan SL (X2) sebesar 56.9\%. Sedangkan sisanya sebesar 43.1\% dipengaruhi oleh faktor lain.

- Tabel 10 yang menunjukkan angka R square 0.755 mengindikasikan korelasi SL (X1) dan TL (X2) terhadap OCB (Y) memiliki hubungan yang cukup kuat karena berada pada range $0.60 \mathrm{~s} / \mathrm{d} 0.799$.

Tabel 11 ANOVA (X1) dan (X2)

\begin{tabular}{llrrrrr}
\hline \multicolumn{7}{c}{ ANOVA $^{\mathbf{a}}$} \\
\hline \multicolumn{2}{l}{ Model } & Sum of Squares & \multicolumn{1}{c}{ df } & Mean Square & \multicolumn{1}{c}{ F } & \multicolumn{1}{c}{ Sig. } \\
\hline \multirow{2}{*}{1} & Regression & 3655,329 & 2 & 1827,664 & 76,669 &, $000^{\mathrm{b}}$ \\
\cline { 2 - 7 } & Residual & 22764,167 & 116 & 23,829 & & \\
\cline { 2 - 7 } & Total & 6419,496 & 118 & & & \\
\hline
\end{tabular}

a. Dependent Variable: VAR00003

b. Predictors: (Constant), VAR00002, VAR00001

Pada table 11 ANOVA terbukti bahwa ada pengaruh yang signifikan antara SL (X1) dan TL (X2) terhadap OCB (Y) pada perusahaan. 
Tabel 12 Coefficients (X1) dan (X2)

\begin{tabular}{|c|c|c|c|c|c|c|}
\hline \multicolumn{7}{|c|}{ Coefficients $^{\mathrm{a}}$} \\
\hline & \multirow[t]{2}{*}{ Model } & \multicolumn{2}{|c|}{$\begin{array}{l}\text { Unstandardized } \\
\text { Coefficients }\end{array}$} & \multirow{2}{*}{$\begin{array}{c}\begin{array}{c}\text { Standardized } \\
\text { Coefficients }\end{array} \\
\text { Beta }\end{array}$} & \multirow{2}{*}{$\mathrm{t}$} & \multirow{2}{*}{ Sig. } \\
\hline & & B & Std. Error & & & \\
\hline \multirow{3}{*}{1} & (Constant) & 7,364 & 3,549 & & 2,075 &, 040 \\
\hline & VAR00001 & ,337 & ,140 & .207 & 2,402 & ,08 \\
\hline & VAR00002 & ,689 & 100 &, 594 & 6,900 &, 000 \\
\hline
\end{tabular}

a. Dependent Variable: VAR00003

Tabel 12 menunjukkan adanya:

$\mathrm{Y}=7.364+0.337 \mathrm{X} 1+0.689 \mathrm{X} 2$

Keterangan:

$\mathrm{Y}=$ Organizational Citizenship Behavior $(\mathrm{OCB})$

$\mathrm{X} 1=$ Servant Leadership (SL), dan X2 = Transformational Leadership (TL)

Kesimpulan dari persamaan regresi tersebut:

- Nilai konstanta 7.364 artinya jika tidak ada kenaikan nilai dari variabel SL (X1) dan TL (X2), maka nilai OCB (Y) adalah 7.364.

- Nilai SL (X1) 0.337 dan TL (X2) 0.689 artinya, semakin tinggi tingkat SL (X1) dan TL (X2) diterapkan pemimpin, semakin meningkat OCB $(\mathrm{Y})$ pada perusahaan.

Dari hasil pengolahan data hal-hal yang dapat disampaikan sebagai hasil dan pembahasan adalah:

1. Variabel $S L(\mathrm{X} 1)$ terhadap $O C B(\mathrm{Y})$ adalah berpengaruh secara signifikan sebesar $45.5 \%$. Artinya bila pemimpin memiliki peran pemimpin yang melayani, $O C B$ akan meningkat, begitu juga sebaliknya. Berdasarkan hasil kuesioner yang dibagikan kepada 117 responden, angka $S L$ (X1) terhadap $O C B$ (Y) adalah 0.455 , dimana indikator "service" memiliki skor tertinggi, sedangkan "emotional healing" memiliki skor paling rendah. Tampaknya kinerja kepemimpinan yang bermuatan SL berdampak langsung terhadap perusahaan sehingga dapat disimpulkan bahwa semakin tinggi pengaruh $S L$ dari pemimpin terhadap karyawan, baik itu memberikan tujuan, memotivasi dan mengembangkan dirinya, maka semakin baik kinerja OCB karyawan. Kondisi yang mensyaratkan OCB menghendaki pemimpin yang mampu membuat seluruh karyawan merasa bagian dari perusahaan, ada ikatan emosional yang kuat antara dirinya dan perusahaan sehingga tanpa diminta pun mereka dengan sukarela memikul tanggung jawab yang secara job des hal itu bukan merupakan tugas dan tanggung jawabnya. Situasi ini memungkinkan terjadi, bila pertama; pemimpin memperhatikan setiap kepentingan anggota tim kerjanya yang membuat setiap individu dalam tim merasakan dirinya berdaya guna dan dibutuhkan dalam kelangsungan kerja tim. Kedua, pemimpin bersedia mendengar dan bila diperlukan menindaklanjuti gagasan atau aspirasi bawahannya dengan tujuan meningkatkan performa organisasi secara keseluruhan. Ketiga, pemimpin secara konsisten mengarahkan semua karyawan untuk bekerja sesuai dengan visi, misi, tujuan atau pun program-program yang telah ditetapkan organisasi secara jangka panjang. Studi terbaru tahun 2020 yang dilakukan oleh Elche et al menunjukkan bahwa SL juga dapat mempengaruhi OCB secara tidak langsung melalui variabel mediasi "empathy" untuk karyawan secara individu dan variabel mediasi "service" untuk karyawan dalam kelompok. Implikasinya, pemimpin dalam hal ini supervisor bila menerapkan kepemimpinan yang empati terhadap anak buah secara individu dan menerapkan kepemimpinan yang melayani dalam kelompok, hal ini meningkatkan OCB karyawan (Elche et al, 2020).

2. Variabel TL (X2) terhadap Organizational Citizenship Behavior (Y) berpengaruh secara signifikan sebesar 58.9\%. Kepemimpinan transformasional adalah kepemimpinan yang dipercaya efektif dalam mempengaruhi bawahan untuk mengubah perilakunya menjadi seperti yang diharapkan. Asumsi dari kepemimpinan jenis ini adalah bahwa setiap individu membutuhkan figure atau teladan yang dapat memberi mereka inspirasi guna melakukan visi atau tujuan yang jelas yang telah ditetapkan, juga caracara dan dukungan yang mereka perlukan untuk tercapainya tujuan tersebut. Selain itu, pemimpin 
transformasional yang efektif memberikan energi dan semangat yang positif terhadap anggota dan lingkungannya berada. Angka 0.589 pada TL terhadap OCB terbukti memiliki ikatan yang sangat kuat. Berdasarkan hasil temuan skor rata-rata indikator "Idealized Influence Behavior" menempati posisi terendah dari jawaban responden, tampaknya pemimpin belum memiliki ide-ide kreatif yang mempengaruhi karyawan agar dapat menjalankan pekerjaannya dengan baik. Hasil studi Shuja Iqbal et al. tahun 2019 menyebutkan bahwa ada korelasi positif dan signifikan TL terhadap OCB. Lebih lanjut, penelitian ini juga mngungkapkan adanya relasi positif dan signifikan OCB terhadap Retensi Karyawan. Selain itu, OCB memiliki efek mediasi yang positif terhadap hubungan antara TL dan retensi karyawan. Dan komunikasi secara positif memoderasi TL dan juga hubungan retensi karyawan dalam OCB. Hasil studi ini mengungkapkan bahwa TL dan komunikasi memainkan peran penting dalam hubungan OCB dan retensi karyawan. Dengan demikian, manajemen perusahaan perlu memberikan perhatian khusus pada variabel-variabel ini. Melihat data turnover perusahaan yang masih tinggi, variabel TL dan komunikasi yang efektif menjadi kunci dalam menyelesaikan masalah yang berhubungan dengan retensi karyawan, sehingga produktivitas dan pertumbuhan organisasi dapat tercapai.

3. Variabel $S L(\mathrm{X} 1)$ dan $T L(\mathrm{X} 2)$ baik secara parsial maupun secara simultan berpengaruh terhadap $O C B$ (Y) secara signifikan sebesar 43.1\%. Dari hasil ini juga terungkap bahwa $T L$ (X2) memiliki pengaruh yang lebih besar dibandingkan dengan $S L(\mathrm{X} 1)$ terhadap $O C B(\mathrm{Y})$. Hal ini sepertinya menunjukan bahwa TL atau kepemimpinan transformasional secara langsung mempengaruhi pembelajaran organisasi, kepercayaan interpersonal dan OCB. Studi yang dilakukan oleh Kim dan Park (2019) menyebutkan bahwa peran kepemimpinan transformasional sangat besar dalam mewujudkan perilaku yang diharapkan dalam OCB. Kepercayaan interpersonal memiliki pengaruh positif dan signifikan terhadap pembelajaran organisasi dan OCB; pembelajaran organisasi memiliki efek langsung dan signifikan terhadap OCB; dan pembelajaran organisasi memediasi hubungan antara kepemimpinan transformasional dan OCB. Artinya, untuk mewujudkan perilaku yang diharapkan dalam OCB dibutuhkan pemimpin yang kuat dan berpengaruh terhadap anak buahnya.

\section{KESIMPULAN}

Adapun kesimpulan dari penelitian ini mengungkapkan bahwa faktor yang paling berpengaruh terhadap Organizational Citizenship Behavior (OCB) adalah Transformational Leadership (TL). Sedangkan yang kedua yang mempengaruhi OCB adalah Servant Leadership (SL). OCB akan meningkat apabila tingkat TL dan SL juga meningkat.

Penelitian terhadap variabel-variabel lain terhadap OCB dapat dikembangkan lebih lanjut karena variabel SL dan TL berpengaruh sebesar $43.1 \%$ terhadap OCB sedangkan sisanya $56.9 \%$ dipengaruhi oleh variabel lain.

\section{DAFTAR PUSTAKA}

EJ Kim, S Park. (2019). The role of transformational leadership in citizenship behavior. International journal of manpower, 2019 - emerald.com

D Elche, P Ruiz-Palomino (2020). Servant leadership and organizational citizenship behavior. International Journal of Contemporary Hospitality Management.

H. Masram \& Dr. Hj. Mu'ah. (2015). Manajemen Sumber Daya Manusia $1^{\text {st }}$ Edition. Sidoarjo: Zifatama Publisher.

K Inkpen, G Oster, M Koch. 2018. [PDF] Proceedings of 16th European Conference on Computer-Supported Cooperative Work-Panels, Posters and Demos. eusset.eu.

MJ Stevens, MA Campion. (1994). The knowledge, skill, and ability requirements for teamwork: Implications for human resource management. Journal of management, 1994 - journals.sagepub.com

M Mu'ah. (2015). Manajemen Sumber Daya Manusia. Sidoarjo: Zifatama

Pengaruh Kepemimpinan Servant dan Kepemimpinan... (Melva Hermayanty Saragih, et al) 
Nasra, M. A., \& Heilbrunn, S. (2015). Transformational leadership and organizational citizenship behavior in the Arab educational system in Israel: The impact of trust and job satisfaction. Educational Management Administration \& Leadership, 44(3), 380-396.

Podsakoff, P. M., Mackanzie, S. B., \& Podsakoff, N. P. (Eds). (2018). The Oxford Handbook of Organizational Citizenship Behavior. Florida

R Salehzadeh. (2017). Which types of leadership styles do followers prefer? A decision tree approach, International Journal of Educational Management, 2017 - emerald.com

Rahayu, N. G. (2015). Pengaruh Kompetensi Auditor Dan Skeptisisme Profesional Auditor Terhadap Upaya Auditor Dalam Mendeteksi Kecurangan (Survey Pada Kantor Akuntan Publik Yang Terdaftar di Otoritas Jasa Keuangan (OJK) Bandung) (Doctoral dissertation, Fakultas Ekonomi Unpas).

Razaki, R. L. (2016). Kontribusi Pemimpin Perusahaan untuk Indonesia. (Online). Diakses 18 Februari 2020 dari https://ppm-manajemen.ac.id/id_ID/blog/artikel-manajemen-18/post/kontribusi-pemimpin-perusahaan-untuk-indonesia-1446

Suyitno, P. P. W., \& Herlawati, H. (2015). Metode Regresi Linier Berganda Kualitas Super Member Supermall Terhadap Peningkatan Jumlah Pengunjung Pada Supermall Karawang. Bina Insani ICT Journal, 2(2), 101-116.

Shuja Iqbal et al. (2019). The Impact of Transformational Leadership on Employee retention: Role of Organizational and Communication. JMIR Preprints 